\title{
INTERVIEW
}

For reprint orders, please contact: reprints@futuremedicine.com

\section{Breast cancer: taking control}

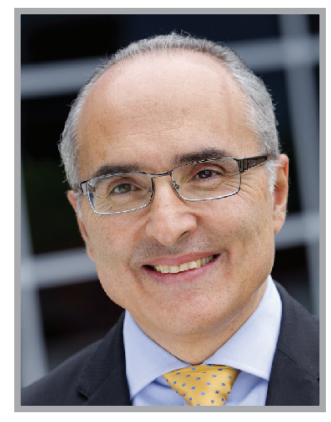

John Boyages* speaks to Joanna Milburn, Commissioning Editor: John Boyages is a cancer specialist with 30 years' experience in the diagnosis and treatment of breast cancer. He was the founding director of the Westmead Breast Cancer Institute (Australia) and has published more than 135 research and clinical articles. He is committed to the dissemination of research findings to lay and professional audiences. He trained at Westmead Hospital and the Dana-Farber Cancer Institute in Boston (MA, USA). He was appointed Director and Professor of Breast Oncology at the Macquarie University Cancer Institute (Australia) in November 2011. He is a clinician and a radiation oncologist at Genesis Cancer Care at the Macquarie University Hospital. He is the author of 'Breast Cancer: Taking Control' (for patients) and 'Clinical Breast Examination: Taking Control' (for health professionals) and the soon-to-be-published 'DCIS of the Breast: Taking Control'. In 2013, he was one of four finalists for the New South Wales Australian of the Year.

Q You have over 30 years' experience in the diagnosis \& treatment of breast cancer: where did it all begin?

I went to Sydney University (Australia) and got into medicine by one mark, so that was my first bit of luck! My second piece of luck was that the Australian Government of the time moved from paid education to free education. I am not sure that my parents would have been able to afford putting me through medical school, or how much that would have cost in those days.

When I finished my medical degree, Sydney Hospital (the first hospital of the colony in Australia) where I had trained was closing down. The government had built a brand new hospital in western Sydney (Westmead Hospital) - this is where I started my residency and was initially being groomed to be general physician.

\section{Q What sparked your interest in radiation oncology?}

During my residency at Westmead Hospital, I was rotated to a term in radiation oncology under Professor Allan Langlands, who was Scottish-trained from the Edinburgh Royal Infirmary (UK). Professor Langlands was the founding professor at Westmead. He was a visionary leader and was really pushing breast conservation in Australia at the time, as many patients were getting mastectomies. He got me very interested in breast cancer and I wrote many papers with him. So in the end, I decided to apply for radiotherapy instead of becoming a general physician. Everybody thought I had gone mad at the time.

\section{Q Describe one of your first key experiences with cancer patients?}

I was working as an intern with a group of surgeons and physicians who were looking after patients with a new diagnosis of cancer, but would give them very little information. Surprisingly, some physicians would not even mention the word 'cancer' at all - this was in the early 1980s. I was often left trying to talk to both the relatives and the patient, balancing a fine line between
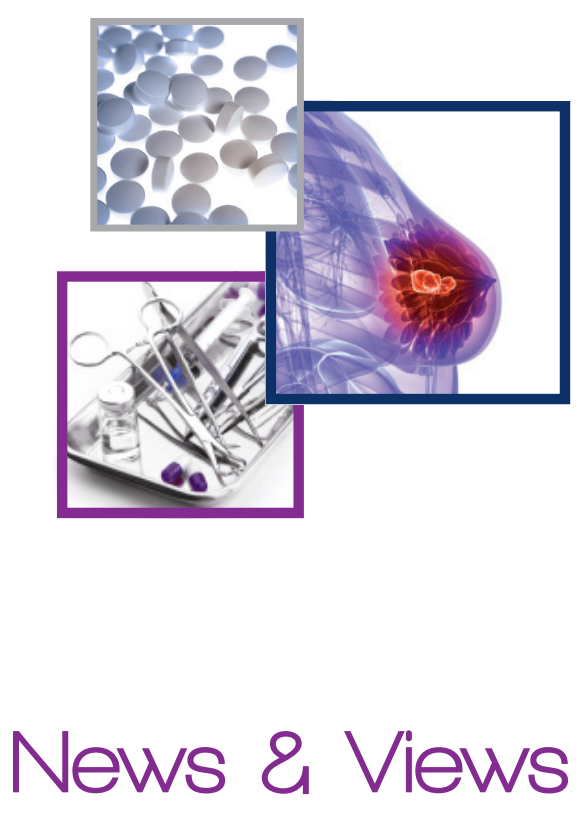

News

Journal Watch

Ask the Experts

Interview

Conference Scene

* Macquarie University Cancer Institute, Macquarie University Hospital, Australian School of Advanced Medicine,

2 Technology Place, Macquarie University, NSW 2109, Australia; Tel.: + 6129812 3508; Fax: +61 29812 3600;

john.boyages@mq.edu.au johnb@bci.org.au

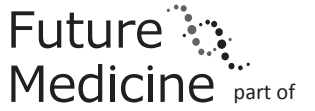


telling them about the diagnosis and not undermining my boss's instruction: not to mention the ' $\mathrm{C}$ ' word. It was a relief when I started seeing patients in the radiotherapy unit, where I found the doctors to be more patient-focused and comfortable about having an open discussion about cancer, its treatment and prognosis. I also found the discipline more technically challenging in terms of physics and anatomy, and that really interested me. The more experience I got, the more I liked it, especially helping patients with breast cancer, and that eventually became my full career.

\section{Q How did your research interests} evolve once you finished your residency? The same week I had finished my final exams (and thought my study was over!), I was invited to take up a fellowship at Harvard University (MA, USA) under the supervision of Professor Jay Harris, who was - and still is - one of the leading breast cancer radiation oncologists in the world. Of course, I then had to sit the American Board entrance exams, so my study was not quite over. The fellowship involved attendance at multidisciplinary breast cancer clinics at the Dana-Farber Cancer Institute (MA, USA), intensive research, a 3-month clinical term at the Beth Israel Hospital (MA, USA) and attendance at weekly breast cancer tumor board meetings.

It was this time in the USA that really opened my eyes to what we could achieve for patients, which I hoped to bring back to Australia. The doctors there were working in teams with a lot more resources. I worked with an amazing team, including Drs Susan Love, Craig Henderson, Dan Hayes and many others. We would see patients together who had been referred from all over the world. At the end of my fellowship, I was offered an Assistant Professorship at Boston, but decided to return to Australia in 1989 to take up the position of Staff Specialist in Radiation Oncology back at Westmead Hospital - a tough decision.

Q What changes in patient care did you implement on returning to Australia? The design of the radiotherapy unit back at Westmead was not ideal: patients were seen in tiny rooms and were weighed in public, so there were things I just did not like back in those days. I spent my whole life trying to improve these conditions and would eventually go on to obtain funding and design the Breast Cancer Institute (BCI), not only from a physical perspective, but also from a 'one-stop-shop', patient-centered service perspective.

In 1990, I very quickly started the Western Areas Breast Group and invited doctors to come together in monthly multidisciplinary team meetings. In 1992, nearly 400 patients were treated by 70 different surgeons - an average of six patients each - and the care was totally fragmented. For example, if you saw a surgeon that operated on five patients a year, their mastectomy alone rate, without radiation, was approximately $65 \%$; however, if you saw a surgeon operating on more than ten patients a year, the rate was more like $35 \%$, and so the remainder had a lumpectomy and radiotherapy. It was my passion to change this, particularly after seeing what can be done in the USA.

From there, we started training specialists of the future, and so we began a fellowships program. I have trained over 40 fellows in my 15 years since the BCI was formed in 1995.

I also had the opportunity to run the first screening program in western Sydney. I started accreting surgeons to our screening program and implemented a general practitioner education program. The unit grew very quickly and we had the lowest cost per screen in the country in 1993 . We then established other local units and two mobile units, and then expanded to shopping center locations.

How did you build on the success of the Breast Screen program in terms of patient treatment?

We started lobbying the government to look at the treatment side of the equation. One in four women were being diagnosed through Breast Screen, whereas three in four women were diagnosed by other methods. However, the patients diagnosed through Breast Screen had better access to treatment than patients diagnosed via other methods, where the infrastructure was more fragmented. In March 1995, we won a government tender to set up the BCI, accredited surgeons, reduced variation in care and introduced state-wide protocols and regular patient information sessions. We worked on the two sides of the spectrum: informing patients and educating doctors about best practice.

\section{Q What initiatives did you implement at the $\mathrm{BCl}$ ?}

I became the Director of the BCI in 1995. After many years of negotiation, we finally built the comprehensive breast center and an imaging center. We had all our equipment in one place, which would be shared by all women - not just those diagnosed through Breast Screen. We set up multidisciplinary teams and had the first digital mammogram in Australia. We started comprehensive systems of care and electronic processes. We also began developing a series of peer-reviewed and patient-reviewed fact sheets and annual public forums televized live across Australia and New Zealand.

\section{Q What was your vision when} developing the fact sheets at the $\mathrm{BCI}$ ? My vision was to empower doctors and to empower patients. The clinical guidelines that patients received were very thick and very scary. I liked the concept of a fact sheet: just a few pages of bite-sized information of where the patient is in their treatment. For instance, there is no point in telling a patient about chemotherapy if they do not need chemotherapy. The fact sheets are still available online and are used all over the world [1].

\section{Q What inspired you to write your book 'Breast Cancer: Taking Control'?}

One evening, I took a phone call from a doctor whose wife had been diagnosed with breast cancer. She was pregnant and had already had a mastectomy: she was told she needed an early cesarian section and had been given no support from her oncologists. I was so angry. If doctors could not get the proper treatment for their wives, then what hope did the general community have? So from that weekend I started writing the book: that was the trigger point for me. Then I kept writing. I enjoy writing - I use a lot of gardening analogies in my consultations and my book. I have nearly finished another 
book for patients titled 'DCIS of the Breast: Taking Control'. My DVD 'Clinical Breast Examination: Taking Control' is aimed at teaching health professionals about how to take a history, examine the breast, where to look for recurrences and how to perform the triple test. I find that most doctors I meet during their training struggle doing a proper breast examination.

\section{Q What attracted you to your new appointment at the Macquarie University?}

I am a builder - I enjoy designing and building new programs. After 17 years as the director of the BCI, and after finally integrating the screening program as an important step in the breast cancer treatment program, having 70 staff, multiple centers, exceptional clinicians and a healthy budget, it was time to move on. The technology at Macquarie University Hospital is mind-blowing. We installed the first contrast mammogram in Australia and our patients have access to PET scanning with an on-site cyclotron. We have also introduced a new technology called volumetric assistance technology, or VMAT, which is particularly useful for patients with leftsided breast cancer or with breast implants receiving post-mastectomy radiation. It is a technique that delivers a high dose where the cancer is and a lower dose around the normal tissue. It is like painting on the radiotherapy. The hospital is a dynamic, 'can do' place and it is centered in a wonderful, agile university, nearly 50 years old with wonderful academic staff and researchers.
Q What has been the proudest moment in your career?

It is difficult to say. Building eight digital breast screening units (in 8 months), four in public hospitals and four in the lingerie department of Myer department stores, was pretty special. But finding out that the reduction in breast cancer mortality in the Greater Western Region of Sydney was the highest in New South Wales (it fell by 33\% from 1991 to 2005) was pretty special, as I felt that coordinated care (linking screening and treatment by using common staff and facilities) was never really embraced by government bureaucracies.

\section{Q What new projects are you currently working on?}

I am enjoying applying the skills I have developed over the years, diagnosing and treating breast cancer, to develop, as the Head of Cancer at Macquarie University, similar programs in areas such as brain cancer, head and neck cancer and prostate cancer. I am also particularly excited about establishing a new advanced lymphedema research program in terms of clinical, psychological, imaging and molecular biology. We have established a one-stopshop advanced lymphedema clinic offering advice about liposuction and lymph node transfers (autologous transplant).

\section{Q How do you hope to see breast cancer treatment change in the next} $5-10$ years?

In many ways, we are still quite rudimentary in our approach. I am hoping that early detection will improve with blood tests and markers rather than mammography. Pathology reports will become more tailored to treatments based on genetic 'oncomapping' of an individual's tumor and radiation will continue to be more precise. We will see more and more targeted agents such as trastuzumab and lapatanib merge, with more oral therapies that target the cancer cell rather than chemotherapy that affects the whole body.

Q What, for you, is the best philosophy in patient care?

To me, it is about listening to your patients, talking to them, making sure you find a treatment plan that is right for them and trying to not push what you think is right. Above all, show genuine care and empathy.

\section{Financial \& competing interests disclosure}

$J$ Boyages receives royalties for the sales of the books mentioned in this article. J Boyages has no other relevant affiliations or financial involvement with any organization or entity with a financial interest in or financial conflict with the subject matter or materials discussed in the manuscript apart from those disclosed.

No writing assistance was utilized in the production of this manuscript.

\section{Website}

1 Westmead Breast Cancer Institute. Fact sheets. www.bci.org.au/about-breast-cancer/ fact-sheets.html 